\title{
IMPACT OF OUTSOURCING OF HUMAN RESOURCES ON TEAM PERFORMANCE IN A POLISH MINING COMPANY \\ Ewelina Wlodarczyk ${ }^{1}$
}

\begin{abstract}
Motivation: In recent years outsourcing of a variety of different activities has been more commonly observed in the coal mining industry. It is connected with employing workers through external companies. These practices are not necessarily perceived as good ones by employees.

Approach and results: This article aims to present how workers perceive these practices. Therefore, two surveys have been conducted. The first, of outsourcing underground work to third-party vendors, was carried out in a group of randomly chosen underground workers of a mining company (PGG Sp. z o.o.). The other survey, also of outsourcing underground work to thirdparty vendors, was carried out in a group of workers of a third-party vendor working for PGG Sp. z o.o.

Conclusions: Analysing the results from the surveys allowed for a better understanding of the reasons for the disapproval of outsourcing underground work. This in turn may be used for better human resource management in coal companies including in particular planning an incentive based pay systems
\end{abstract}

JEL Classification Numbers: M12, M54, L29, DOI: 10.12955/cbup.v7.1383

Keywords: mining, management, human resources management, outsourcing

\section{Introduction}

Conventionally, enterprises were perceived as highly integrated organisations which owned and managed all resources in the full scope of their activities. However, over time, a growing scale of operations, business complexity and growing competitiveness made companies consider more flexible business models and start searching for different strategies, e.g. outsourcing (Oshri, Kotlarsky, \& Willcocks, 2011). Beyond doubt, the necessity of reacting to market changes and problems in forecasting the future direction of changes means that the companies must concentrate on their core competences and capabilities (McIvor, 2008). As a result, instead of performing all activities on their own, the enterprises were searching for specialists with a high level of expertise in their fields and offering services the organisations required at lower cost. Thereby, the enterprises are able to save valuable time and money and concentrate on the elements they have done most successfully (Suhasini, Rajan, \& Sushma, 2013). Thus, the outsourcing concept has evolved from the demand for better and more flexible organisations and has become a significant business approach, as a competitive advantage can be built when products are produced and services performed by third-party vendors (Yang, Seongcheol, Changi, \& Ja-Won,, 2007).

Conventionally, outsourcing is defined as work performed for a company by individuals who are not full-time employees of the enterprise. Otherwise, this is contracting from a third-party vendor services to manage the completion of certain work, for a defined time, at defined cost and level of services. In modern working conditions outsourcing can be highly complex and organisations use outsourcing of vendors for numerous reasons. According to analysts, the enterprises mostly give cost reduction as the most important reason for outsourcing (Deepa \& Seth, 2011). Unfortunately, in outsourcing processes the personnel matters are most often undervalued. It results from the fact, that in outsourcing solutions technical and legal aspects or the service concepts are underscored, whereas, the full impact of persons is not fully taken into account. As a consequence, outsourcing is not always well perceived by the employees, as many individuals do not accept loss of standard jobs, or consider such practices as a reason of practical problems and concerns (Leighton, 2007).

The bituminous coal market in Poland is characterised by regularities in coal mining and sales levels during a year. The seasonal nature of these is connected with an increase of the consumption of coal in the heating season and its decrease in the summer. Moreover, the mining level is influenced by other factors, such as geological-mining conditions, available resources or the mining method. Nevertheless, every year, because of considerable seasonal fluctuations, the mining companies have to withstand factors of production surplus in a so called "low season" and shortage in periods of increased demand for bituminous coal (Rybak \& Rybak, 2016). For this reason, in recent years it is more and more common

\footnotetext{
${ }^{1}$ Silesian University of Technology, Faculty of Mining and Geology, Department of Safety Engineering; ewelina.wlodarczyk@polsl.pl
} 
to outsource different jobs/services to third-party vendors. Obviously it involves hiring employees through these companies.

\section{Methodology}

As it was mentioned before it has recently become more common to contract out a variety of activities/services in bituminous coal mining. It is connected with employing workers through external companies. These practices are not necessarily perceived as good ones by employees because they may influence directly or indirectly their remuneration and consequently their work motivation. It is therefore appropriate to examine the way employee see outsourcing. Therefore, two surveys were conducted. The first, on outsourcing underground work to third-party vendors, was carried out in a group of randomly chosen underground workers of a mining company (PGG Sp. z o.o.). The other survey, also of outsourcing underground work to third-party vendors, was carried out in a group of workers of a thirdparty vendor working for PGG Sp. z o.o. The surveys were anonymous which if not done, obviously might have influenced respondents' honesty in answering. Analysing the results of the surveys allowed for better understanding of the reasons of disapproval of outsourcing underground work. This in turn may be used for better human resources management including in particular planning an incentive based pay system.

In both surveys minimum sample size was determined in accordance with the formula:

$$
\mathrm{n}=\frac{N u_{\alpha}^{2} w(1-w)}{(N-1) d^{2}+u_{\alpha}^{2} w(1-w)} \text {. }
$$

Where:

$1-\alpha \quad$ is the confidence level

$\mathrm{N} \quad$ is the general population size,

$\mathrm{w} \quad$ is the estimated fraction size based on following calculation: $\mathrm{w}=\mathrm{k} / \mathrm{n}, \mathrm{k}=0,1,2 \ldots, \mathrm{n}$, where $\mathrm{k}$ is the number of selected elements in the sample (Kasperowicz-Ruka, 2017).

The survey assumed:

1) A confidence level $1-\alpha=0.95$, thus $u \alpha=1.96$, therefore $u^{2} \alpha=3.8416$;

2) Maximum margin of error (statistical) $d=10$, therefore $d^{2}=0,01$;

3) Estimated fraction size $w=0.5$; therefore expression $w(1-w)$ is $0.25-$ which is maximum value for the expression for each $\mathrm{w} \in<0 ; 1>$;

4) For calculation of minimum sample size of $\mathrm{PGG}$ employees $\mathrm{N}=32,000$ (the number of all workers employed at PGG Sp. z o.o.);

5) For calculation of minimum sample size of third-party vendor employees $\mathrm{N}=150$ (the number of all workers working underground for PGG Sp. z o.o.);

Calculations and underlying assumptions show that there should be a survey carried out with a minimum of 96 persons employed at PGG Sp. z o.o. This value was rounded up to 100 persons and the maximum (statistical) margin of error of fraction of elements selected from the statistical population of N elements was calculated. It equals $9.78 \%$. Therefore, the survey was carried out with 100 randomly chosen underground workers of the mining company. Maximum margin of error is $9.78 \%$. Accordingly, the calculations for third-party vendor showed that there should be a survey carried out with at least 59 employees of the company. The number was rounded up to 60 with a maximum margin of error of $9.80 \%$.

As it was mentioned before the survey was carried out on a group of underground workers exclusively, which without any doubts has an impact on the validity of the study.

The first two questions referred to age and job seniority. Figure 1 shows that the age of respondents was varied.

Taking into consideration the age of respondents it is noticeable that as much as $30 \%$ of the respondents of the outsourced company are more than 45 years old. When considering employment history in mining, one may notice that it is closely related to age, which is illustrated in Fig. 2. What is more, as previously noted, there is a considerably numerous group of employees older than 45 years in the 
outsourced team as well as those with greater than 25 year employment experience in coal mining, which reflects the fact that outsourcing companies employ retired miners.

The next question to the respondents refereed to the type of employment (Fig.3) and system of remuneration (Fig.4).
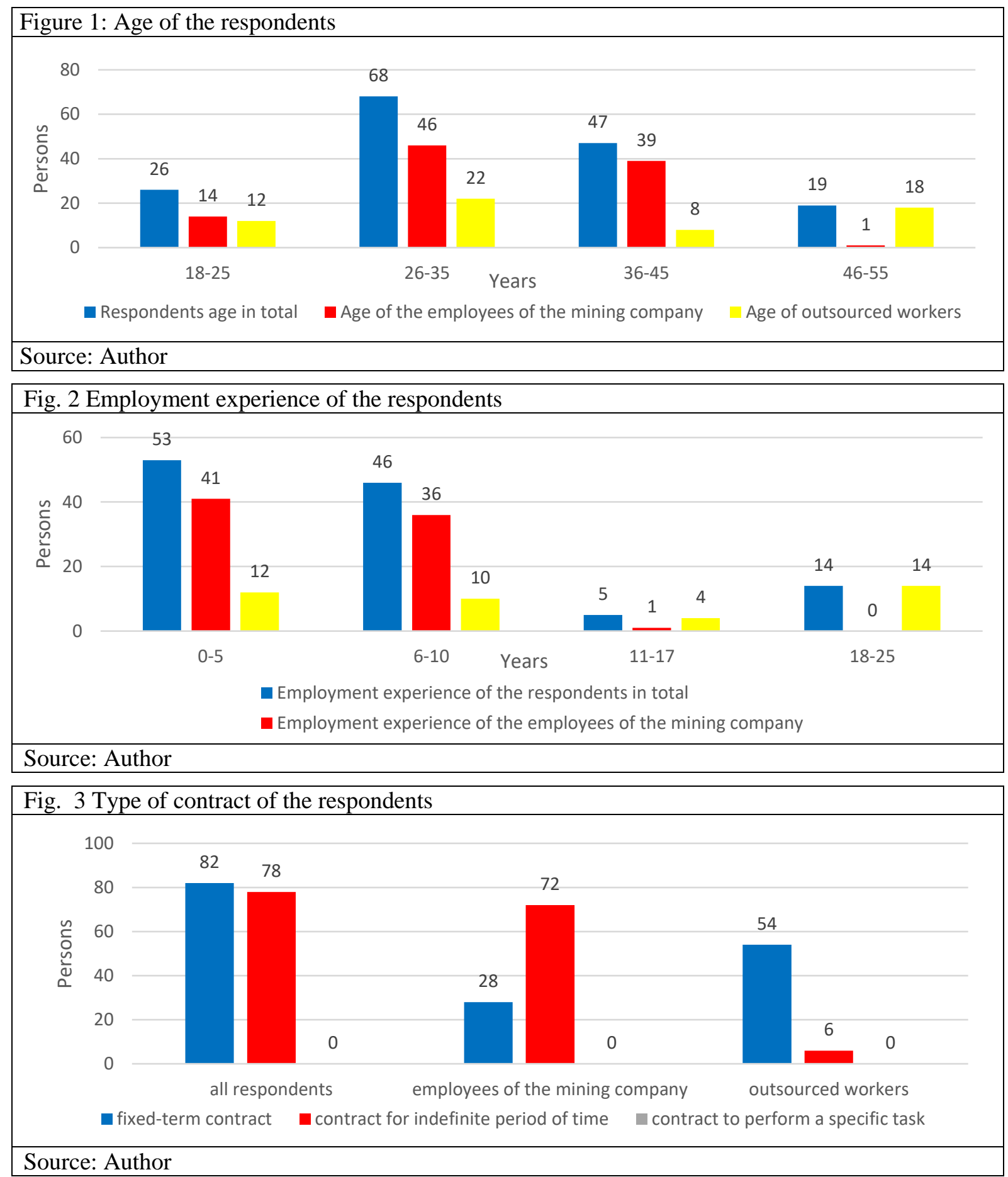

These questions may help assess the employees' approach to work. All the employees had a contract of employment, $52 \%$ of contracts were for an indefinite period and the remaining $48 \%$ were fixed-term contracts. Taking into consideration the employment one may note a considerable difference. Namely, when it comes to the group of the employees of the mining company, a vast majority of them (72\%) had contracts for an indefinite period and the remaining employees had fixed-term contracts. In contrast, the group of outsourced workers shows a reverse proportion, i.e. as much as $90 \%$ of employees had contracts for a fixed period of time and merely $10 \%$ had contracts for an indefinite period of time. 
Analysing the responses referring to the remuneration system it is noted that $73 \%$ of the employees had a work time and bonus based system of remuneration, further $15 \%$ of the respondents have a time rates system. Only $12 \%$ of the respondents have a piecework remuneration system. In the case of the group of the employees of the mining company, the vast majority (i.e. 85\%) had a work time bonus based system of remuneration, further $14 \%$ declared a time rates system and only 1 employee of the mining company had the piecework remuneration system. In the case of the outsourced company the situation is slightly different. Namely, 53\% of the workers had the work time and bonus based system of remuneration, further $30 \%$ of the respondents had the piecework system and only $17 \%$ of the respondents had the time rates remuneration system.

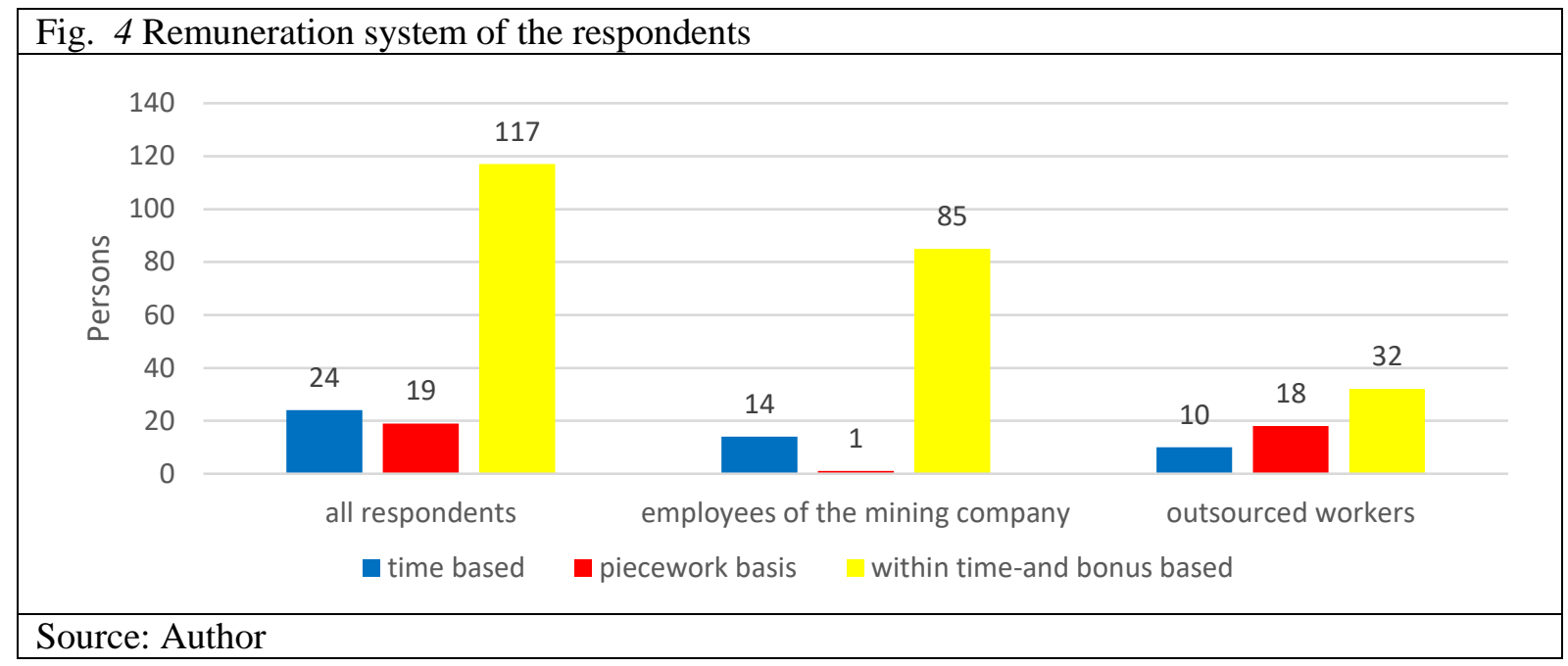

Taking into consideration the fact that the majority of the employees of the outsourced company have fixed-term contracts and their remuneration is related to the work done, one may conclude that this could cause lack of financial stability among the respondents as well as pursuing the highest possible income. Moreover it may result in lack of identification with the workplace.

The following questions referred to the opinion of the respondents on practices of outsourcing by PGG Sp. z o.o. mining work (Fig.5) and the influence of those practices on workforce productivity (Fig.6), standards (Fig.7) and remuneration (Fig.8) of the group of the employees of the mining company.

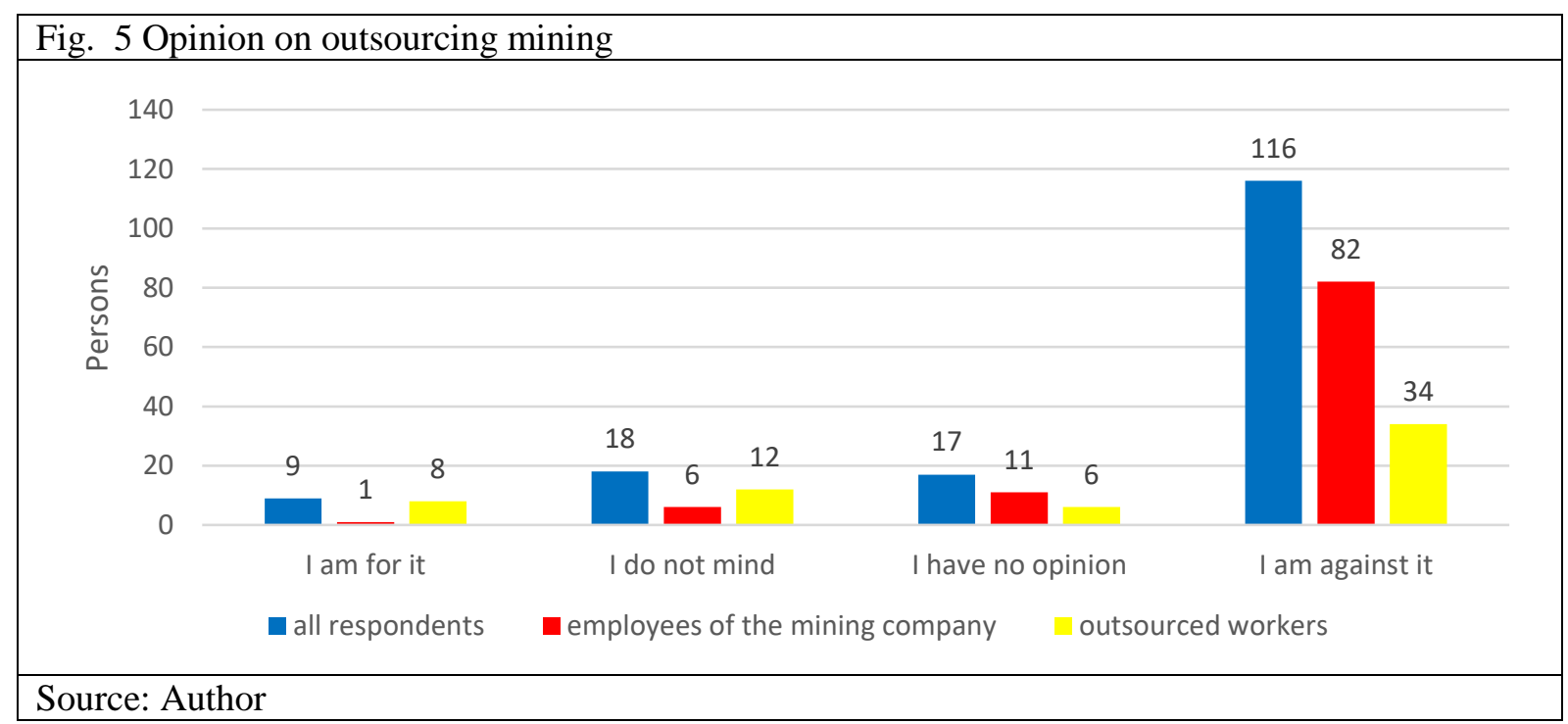

As can be seen a vast majority (i.e. $72 \%$ ) of the respondents are against outsourcing the mining work. $11 \%$ of the employees do not mind and $11 \%$ have no opinion on this matter. However, only $6 \%$ of the respondent had a positive attitude towards such practices. Analysing the question by the place of employment then as much as $82 \%$ of the respondents being employees of the mining company are against such practices, $11 \%$ have no opinion, further $6 \%$ do not mind and only one respondent chose "I 
am for". Such a strong aversion to outsourcing mining work may be the result of its impact on the market and consequently the remuneration of mining company employees. However, views of the group of outsourced workers are more divided. Nevertheless as much as $57 \%$ are against outsourcing mining work, $20 \%$ do not mind, $10 \%$ have no opinion on this matter and $13 \%$ are for it.

The negative attitude of the employees of outsourced companies might be resulting from their awareness of the fact that such practices cause reduction in the employment by mining companies and thus they do not have the chance of being employed by mining companies. This, in turn, has an impact on their remuneration as outsourcing companies offer worse remuneration to their employees than the mining companies. Furthermore, there are other benefits in mining companies, such as "Barbórka" (in Poland it is a Miner's Day or St Barbara's Day celebrated on $4^{\text {th }}$ December, on this day some of the miners receive an extra payment) or so called "14" (it is an annual bonus, the amount depends on job seniority and type of work performed), which do not necessarily take place in private enterprises. Moreover, such solutions enable retired miners to be employed, which surely is not well perceived by young workers. It has been confirmed by the survey. In the analysis of the responses referring to the opinion on outsourcing mining work, seniority of employees was taken into consideration. As clearly seen in the survey, the persons who were against such practices were respondents with seniority up to 25 years. Furthermore, all respondents who were for outsourcing mining work were in the group of employees with more than 25 year experience in the mining industry.

Beyond any doubt outsourcing work of retired miners has a negative impact on the employment market. Firstly, employed miners entail reduction in the number of places on the labour market. Furthermore, an employer who employs a retired worker bears lesser staff costs. Secondly, employees who are pensioners cannot exceed a specified income threshold because this will result in a reduction of their pension. Therefore the employees who are pensioners, are more willing to receive wages at lower rates. This, in turn, has an impact on the whole labour market lowering workers remuneration.
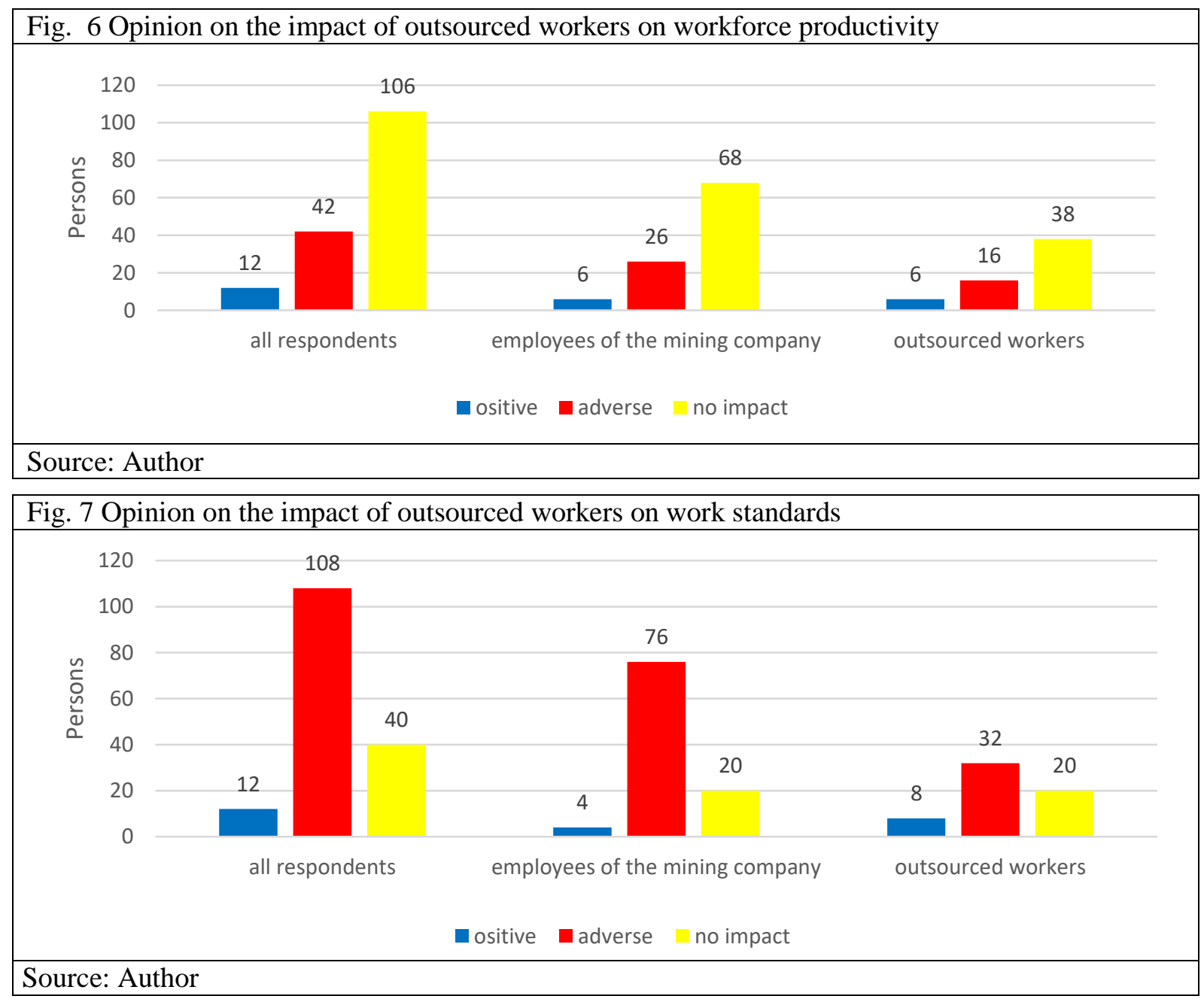
Analysing the opinion of the respondents on the impact of outsourced workers on the workforce productivity of the group of the employees of the mining company (Fig.6) it can be noted that a vast majority (66\%) think that they do not have any impact on the mining company workforce productivity. $26 \%$ of the respondents think that they have adverse impact and a further $8 \%$ see positive impact. In the case of this question there is significant concordance of the answers between both groups of workers.

However, in the case of the question referring to the work standards, the answers of the respondents are different (Fig.7). As much as 68\% of the respondents think that they have an adverse impact on the work standards of the employees of mining companies. Further $25 \%$ of the respondents do not see any impact on the work standards of the employees of mining companies. Only $7 \%$ of the respondents think that they have a positive impact on work standards applied in mining companies. Just like in the previous question there is significant concordance of the answers between employees of the mining company and the outsourced workers.

The following question was intended to show the opinion of the respondents on the influence of outsourced workers on the remuneration of the mining company employees (Fig.8). Analysing the answers, it can be noted that a vast majority (66\%) of the respondents think that they have a negative impact on the remuneration of the mining company employees. Further $3 \%$ do not see any impact of the outsourced workers on the remuneration of the mining company employees. Importantly, only 3 respondents ticked a positive impact of outsourcing mining work on the remuneration of the mining company employees. Again, there is a concordance between the answers of the mining company employees and the outsourced workers, which is confirmed in Fig. 8.
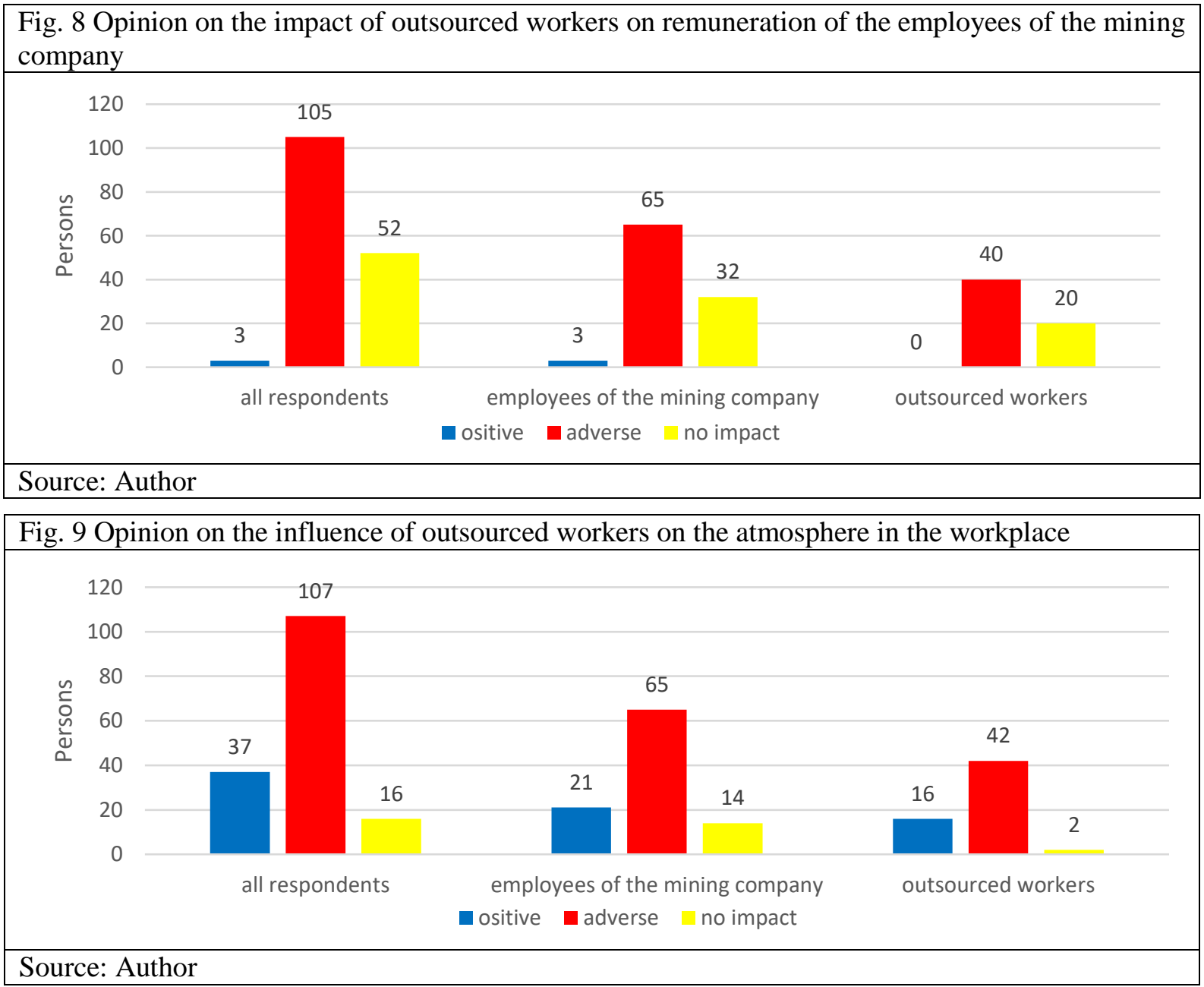

Answers to the three questions prove that both mining company employees and outsourced workers are aware of the impact of outsourcing mining work on the mining company employees. Primarily they are aware of the fact that the mining company employees' remuneration depends on the amount of work 
done. Therefore if outsourced workers work faster they have an impact on work standards of the mining company employees and consequently on their remuneration and work motivation.

This impact may result in a bad atmosphere in the workplace, which is why the respondents were asked about the impact of outsourcing mining work on the atmosphere in the workplace (Fig. 9).

As it can be noted, a vast majority of the respondents think that the impact of outsourcing mining work on the atmosphere in the workplace is adverse. It is mainly caused by the impact of outsourced workers on the remuneration of the mining company employees.

The last question of the survey referred to the compliance of the outsourced workers with health and safety regulations (Fig. 10). 69\% of the respondents think that they do not observe health and safety regulations. However, $31 \%$ think the opposite. It is worth noting that the mining company employees have a more negative opinion regarding this question. Namely, as much as $84 \%$ think that they do not observe the health and safety regulations and only $16 \%$ have positive opinion regarding this question. However, the opinions of outsourced workers are more split, namely, 57\% think that they do not observe health and safety regulations and the remaining $43 \%$ are of the opposite opinion.

It is worth considering whether the divergent views are a result of honesty of the respondents or whether part of them does not want to admit non-observance of the regulations. Nevertheless, a considerable part of the respondents admits that there is a problem regarding compliance with the health and safety regulations. It is very worrying because working underground is extremely dangerous and the workers who do not observe regulations risk their safety if not life. Furthermore, the risk posed by them may be incurred by other co-workers. This, in turn, undoubtedly causes a negative approach of the mining company employees to outsourcing mining work.

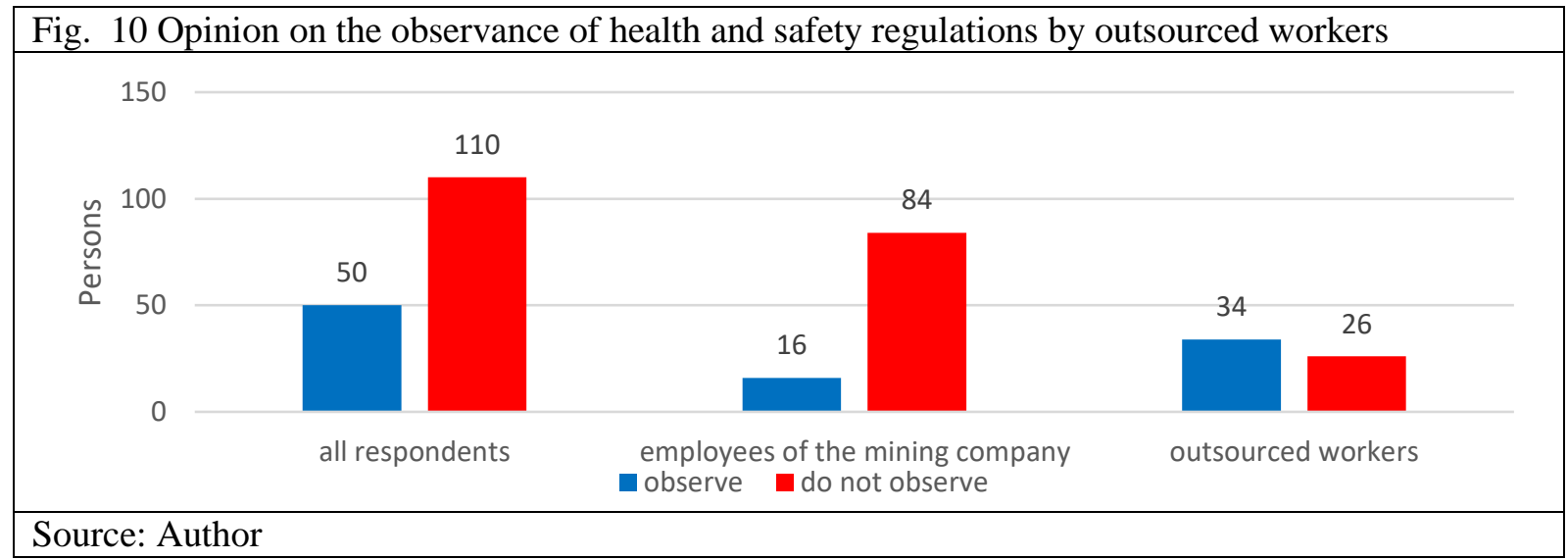

\section{Summary and conclusions}

Undoubtedly outsourcing frequently used in mining companies in Poland reduces their costs but it also has disadvantages. Certainly one of them is the impact on the labour market. Primarily, outsourcing mining work enables retired employees of the mining company to be employed. Obviously this way remuneration in the labour market is reduced and there are fewer workplaces for young employees. Outsourced companies use this solution, however, mainly because of two advantages. Firstly, employing a pensioner is a much cheaper solution for a company at least because of no obligation to pay contribution to the Labour Fund and the Guaranteed Employment Benefit Fund. Secondly, pensioners are more willing to work for lesser remuneration. This is due to the fact that pensioners cannot exceed a specified income threshold because this will result in reduction of their pension.

The survey result showed that outsourcing mining work by mining companies is perceived negatively by both the mining company employees and outsourced workers who are non-pensioners. Primarily because of the fact that these practices reduce remuneration in the labour market and there are fewer workplaces for young employees. Additionally, outsourcing reduces employment in mining companies. Therefore, outsourced workers are aware that if outsourcing was not used they would have a good chance to be employed in mining companies and, consequently, a better remuneration

What is more, outsourced workers have fixed-time contracts and their remuneration depends on the work done. This may cause the respondents' lack of financial stability. As a result they may work more 
efficiently in order to ensure the highest remuneration possible and thus safeguard their future. Consequently this has an adverse impact on remuneration and motivation of mining company employees, whose bonus depends on the work done. Moreover, the mining company employees are aware of that and this is why they think that outsourcing mining work has an adverse impact on the atmosphere in the workplace. This is also confirmed by the employees' opinions. Both employees of coal companies and external outsourcing companies believe that outsourcing of mining workers:

- do not have any impact on the mining company workforce productivity

- have a negative impact on the remuneration of the mining company employees

- have an adverse impact on the work standards of the employees of mining companies or do not have any impact

- have a negative impact on the atmosphere in the workplace.

Additionally, working at a fast pace does not make it easy to observe health and safety regulations, which was confirmed by the survey results. The majority of respondents think that outsourced workers do not observe health and safety regulations. It is worth noting that the employees of the mining company have a more negative opinion on the subject. Namely, as much as $84 \%$ think that they do not comply with health and safety regulations, and only $16 \%$ have a positive opinion on this question. The opinions of external employees are more divided, namely $57 \%$ believe that they do not comply with health and safety regulations, and the remaining $43 \%$ have the opposite opinion. However, this is a very disturbing conclusion because working underground is subject to many kinds of risk, therefore the safety of employees should be vital in a mining company.

In this regard it should be asked whether outsourcing is the best solution. There might be some better cost reducing solutions. Furthermore, the outsourcing of human resources has not been perceived well by employees. Better human resources management within the company seems to be a better solution. Mining companies in Poland usually consist of a few entities called coal mines. Management including, HR management is run independently. Therefore, there is some risk of inefficient use of available human resources on the company's whole- scale. In this regard, it would be advisable to combine employment into one unit in order to manage human resources better within the company and, consequently, reduce outsourcing.

\section{References}

Deepa, S., \& Seth, M. (2011). Human Resource Outsourcing: Analysis Based On Literature Review ,International Journal of Innovation,. Management and Technology, 2(2), pp. 127-135.

Kasperowicz-Ruka, I. (2017, 07 10). Estymacja przedziałowa frakcji elementów wyróżnionych w skończonej populacji. Retrieved from towarzystwobiznesowe.pl: http://www.towarzystwobiznesowe.pl/wgrane_pliki/estymacja-frakcji-wskonczonej-populacji.docx

Leighton, P. (2007). Out of the Shadows: Managing Self-employed,Agency and Outsourced Workers. Oxford: ButterworthHeinemann.

McIvor, R. (2008). What is the right outsourcing strategy for your process? European Management Journal(26), pp. 24-34.

Oshri, I., Kotlarsky, J., \& Willcocks, L. (2011). The Handbook of Global Outsourcing and Offshoring. Palgrave Macmillan. Rybak, A., \& Rybak, A. (2016). Possible strategies for hard coal mining in Poland as a result of production function analysis. Resource Policy(50), pp. 27-33.

Suhasini, R., Rajan, N., \& Sushma. (2013). Human Resources Outsourcing. Asia PacificJournal of Management \& Entrepreneurship Research, 2(1), pp. 87-100.

Yang, D. H., Seongcheol, K., Changi, N., \& J.-W. M. (2007). Developing a decision model for business process outsourcing. Computers \& Operations Research(34), pp. 3769-3778. 